\title{
PERLINDUNGAN HAK-HAK ANAK DALAM UPAYA PENINGKATAN KESEJAHTERAAN ANAK
}

\author{
Oleh: \\ Anissa Nur Fitri, Agus Wahyudi Riana, \& Muhammad Fedryansyah \\ Oleh: \\ (nurfitrianissa@gmail.com; wahyudiriana@yahoo.com; fedry_cons@yahoo.com)
}

\begin{abstract}
ABSTRAK
Artikel ini membahas tentang bagaimana kondisi anak di Indonesia.Khususnya tentang bagaimana pemenuhan kebutuhan anak.Kesejahteraan adalah kondisi dimana semua kebutuhan hidup seseorang bisa terpenuhi dan bisa mencapai kepuasan.Anak adalah salah satu yang harus diperhatikan kesejahteraannya, baik itu kesejahteraan lahir, kesejahteraan batin, maupun kesejahteraan sosialnya karena anak merupakan individu yang akan meneruskan cita-cita bangsa dan menjadi generasi penerus suatu negara.Saat ini, kondisi anak di Indonesia yang masih perlu untuk ditangani oleh pemerintah dan pihak-pihak lainnya karena kesejahteraannya yang bermasalah.Banyak hal-hal yang menjadi penyebab tidak terpenuhinya kebutuhan dan hak-hak anak, pemenuhan hak - hak anak yang dirampas dikarenakan mereka harus bekerja serta pengaruh kondisi psikososial anak ketika mereka bekerja akan mempengaruhi proses pertumbuhan dan perkembangan anak tersebut. Untuk mengurangi permasalahan anak tersebut, pemerintah telah banyak melakukan upaya untuk menanggulagi permasalahan pekerja anak yang menyebabkan anak tidak sejahtera, namun masih belum cukup efektif untuk menyelesaikannya.Tentu saja hal yang seperti ini harus diperbaiki. Karena anak merupakan generasi masa depan yang harus diperhatikan kesejahteraannya agar perkembangannya pun baik. Salah satu yang harus diperhatikan tentang perlindungan dan kebutuhan hak anak adalah tentang efektifitas Undang-Undang Perlindungan Anak, karena dalam undangundang tersebut telah dibahas bagaimana seharusnya kita memperlakukan anak agar anak dapat hidup sejahtera dan mendapatkan perlindungan serta pemenuhan kebutuhan hidup dan haknya.
\end{abstract}

Kata kunci : perlindungan anak, kesejahteraan anak, hak anak.

\section{ABSTRACT}

This article discusses how condition of children in Indonesia. Especially about how to meet the needs of the child. Welfare is a condition in which all one's needs can be met and can achieve satisfaction. Child is one that must be considered well-being, be it welfare of birth, mental well-being, and social welfare because the child is an individual who will carry on the ideals of the nation and become the next generation a country. Currently, the condition of children in Indonesia, which still need to be addressed by governments and other parties because of welfare problems. Many things that cause non-fulfillment of the needs and rights of children, the fulfillment of rights - the rights of children deprived of because they have to work as well as the influence of psychosocial condition of children when they are working will affect the growth and development of the child. To reduce the problems of the child, the government has made little effort to notice child labor issues that caused the child does not prosper, but still not effective enough to solve it. Of course, things like this should be corrected. Because children are the future generation to be aware that development was good welfare. One of them, about the effectiveness of the Child Protection Act, because the law has been 
discussed how we should treat children so that children can live in peace and the protection and fulfillment of life and rights.

Keywords : child protection, child welfare, child rights.

\section{PENDAHULUAN}

Anak merupakan generasi penerus bangsa yang diharapkan dapat bermanfaat di masa depan. Undang-Undang No 4 Tahun 1979 pasal 1 ayat 2 tentang Kesejahteraan Anak menyebutkan bahwa: "Anak adalah seseorang yang belum mencapai umur 21 (dua puluh satu) tahun dan belum pernah kawin". Berbicara tentang hak anak adalah menjadi hal yang menarik karena anak itu unik, ada bermacam-macam yang sangat perlu diperhatikan baik oleh orang tua maupun masyarakat tentang pemenuhan hak-hak anak terutama hak dasar bagi anak.Karena anak merupakan Individu yang utuh yang mempunyai asasi dan harus terpenuhi haknya.Sebagai seorang individu, seorang anak pastinya membutuhkanaspek-aspek yang mendukung perkembangannya. Dalam tumbuh kembangnya, anak haruslah diperhatikan segala macam kebutuhannya.Kesejahteraan anak mengacu pada terpenuhinya segala hak dan kebutuhan hidup anak.

Hak anak adalah hak dasar yang wajib diberikan dan didapatkan oleh anak meliputi anak usia dini dan juga remaja usia 12-18 tahun. Hak anak ini berlaku baik anak yang mempunyai orang tua ataupun sudah tidak mempunyai orang tua, dan juga anak-anak terlantar.Hak anak menjadi sesuatu yang sudah selayaknya didapatkan oleh anak. Menurut KHA(Konvensi Hak Anak) yang diratifikasi kedalam Kepres No 36 Tahun 1997, terdapat 10 Hak Mutlak Anak :

1. Hak Gembira

Setiap anak berhak atas rasa gembira, dan kebahagiaan seorang anak itu harus dipenuhi.

2. Hak Pendidikan

Setiap anak berhak memperoleh pendidikan yang layak.

3. Hak Perlindungan

Setiap anak berhak mendapatkan perlindungan, dilindungi dari segala tindak kekerasan dan penganiayaan.

4. Hak Untuk memperoleh Nama

Setiap Anak berhak memperoleh nama, sebagai salah satu identitas anak.

5. Hak atas Kebangsaan

Setiap anak berhak diakui sebagai warga negara dan memiliki kebangsaan, anak tidak boleh apatride (tanpa kebanngsaan).

6. Hak Makanan

Setiap anak berhak memperoleh makanan untuk tumbuh kembang dan mempertahankan hidupnya.

7. Hak Kesehatan

Setiap anak berhak memperoleh pelayanan kesehatan yang layak, tanpa diskriminasi, anak harus dilayani dalam kesehatan.

8. Hak Rekreasi

Setiap anak berhak untuk rekreasi untuk refreshing, dan anak harus dilibatkan dalam memilih tempat rekreasi yang mereka inginkan.

9. Hak Kesamaan

Setiap anak berhak diperlakukan sama dimanapun dan kapanpun, tanpa ada tindak diskriminasi.

10. Hak Peran dalam Pembangunan

Setiap anak berhak dilibatkan dalam pembangunan negara, karena anak adalah masa depan bangsa. 
Sedangkan untuk hak dasar anak, terdapat 4 hak dasar anak, yaitu :

1. Hak Hidup

Hak hidup ini berlaku dari semenjak anak itu masih dalam kandungan, yang termasuk kedalam hak hidup adalah seperti memberikan gizi dan rangsangan-rangsangan ketika anak masih dalam kandungan, periksa kandungan, dan lain- lain.

2. Hak Tumbuh Kembang

Dalam kehidupan anak, anak harus diberikan kesempatan sebaik-baiknya untuk tumbuh dan berkembang, seperti mendapatan pengasuhan, pendidikan yang baik, jika sakit diobati atau dibawa kedokter, diberi ASI,di imunisasi, dibawa ke posyandu.Selain itu perkembangan Psikisnya pun diperhatikan, seperti memberikan rasa aman dan rasa nyaman, membuat lingkungan kondusif, menjauhkan anak dari hal-hal yang berbahaya, tidak memberikan makanan yang berbahaya bagi perkembangannya.

3. Hak Partisipasi

Maksud dari hak partisipasi disini adalah anak harus dilindungi dari situasi-situasi darurat, menerapkan tentang perlindungan hukum, dan dari apapun yang berkaitan dengan masa depan si anak.

4. Hak Perlindungan

Anak mempunyai hak untuk mendapatkan perlindungan dan menentukan pilihan untuk hidupnya.Anak dalam keluarga harus dibiasakan berbicara, agar anak mempunyai hak suara dan mulai berani menentukan hal-hal yang diinginkan.Contohnya adalah ingin saat anak memiliki keinginan yang berbeda dengan keinginan orangtuanya, maka dicarikan titik temu.Hal ini perlu diperhatikan karena apa yang ditentukan oleh orang dewasa itu belum tentu baik pula bagi si anak, sehingga anak juga diperlakukan sebagai insan yang dimanusiakan.

Jika anak telah merasa bahwa kebutuhan dirinya terpenuhi, anak akan merasa sejahtera. Karena tingkat kesejahteraan anak dapat diukur dari seberapa besarnya kebutuhannya terpenuhi.

\section{PERMASALAHAN MENGENAI PERLINDUNGAN HAK DAN PENINGKATAN KESEJAHTERAAN ANAK}

Sebelum tahun 1992, persoalan yang menyangkut masalah anak hanyalah pada risiko kehidupan dan perkembangannya menjadi manusia. Akan tetapi setelah konferensi mengenai children at risk dibuka di Bergen pada bulan Mei, tahun 1992 persoalan anak tidaklah seputar itu saja. Sebagai dampak dari tidak terpenuhi kebutuhan-kebutuhan anak tentunya akan menimbulkan permasalahan-permasalahan.

Di Indonesia sendiri, masih sangat banyak anak-anak yang jauh dari kata sejahtera.Masih banyak kasus-kasus hukum yang melibatkan anak, padahal sudah ada Undang-undang yang jelas mengatur tentang hal tersebut.Anak yang berkonflik dengan hukum, setiap tahunnya terdapat lebih dari 4.000 perkara pelanggaran hukum yang dilakukan anak-anak di bawah usia 16 tahun. Tahun 1994 terdapat 9.442 perkara, menurun pada tahun 1995 (4.724 perkara).Dari seluruh anak yang ditangkap hanya sekitar separuh yang diajukan ke pengadilan dan $83 \%$ dari mereka kemudian penjarakan.

Selain itu, semakin meningkatnya jumlah anak terlantar.Diperkirakan bahwa pada tahun 2000-an, jumlah anak jalanan yang semula diperkirakan hanya sekitar 50.000, jumlahnya meningkat menjadi sekitar 125.000.Masih berkaitan dengan masalah diatas, banyak juga anak-anak yang menjadi obyek eksploitasi seksual komersial. Diperkirakan pada tahun 2000 ada sekitar 30 persen dari seluruh pekerja seks komersial pada saat itu adalah anak-anak di bawah usia 18 tahun. Data resmi mengenai berapa jumlah yang sebenarnya sangat sulit didapatkan karena mobilitas mereka yang sangat tinggi.Apalagi setelah krisis ekonomi terjadi, tercatat jumlah pekerja seks di Batam jumlahnya 
naik empat kali lipat menjadi 10.000. Jumlah uang yang berputar dalam industri seks di negeri Indonesia berkisar antara 1,8 milyar sampai 3,3 milyar setahun (data tahun 2000).

Menurut data BPS pada bulan Agustus 2000 jumlah pekerja anak sebanyak 2,3 juta. Jumlah ini belum mencakup anak-anak berumur di bawah 10 tahun. IPEC/ILO memperkirakan sekitar 8 juta pekerja anak di bawah usia 15 tahun. Sebagai perbandingan selama tahun 1995-1999 terdapat 11,7 juta anak yang putus sekolah. Sedangkan untuk kasus pelacuran anak, terdapat eksploitasi secara seksual yaitu 40 - 70 ribu anak di bawah umur 18 tahun.Mereka sebagian juga diperdagangkan ke luar negeri.Pada tahun 1997/1998, terdapat 75.106 tempat pekerja seks yang terselubung ataupun yang terdaftar.Kira - kira 30\% penghuni tempat-tempat tersebut perempuan berusia 18 tahun. (Laporan Situasi Anak dan Perempuan,2000).

Selain itu, permasalahan lainnya yang dialami oleh anak yang merupakan dampak dari tidak terpenuhi kebutuhan dasar mereka adalah anak terlantar. Anak terlantar adalah anak yang karena sebab-sebab tertentu tidak terurus, tidak terpelihara, sehingga tidak dapat terpenuhi kebutuhan jasmani, rohani dan sosialnya, yang mengakibatkan terganggu atau terhambat pertumbuhan jasmani dan perkembangan kepribadian anak tersebut. Adapun indikator dari anak terlantar adalah sebagai berikut:

a. Anak umur 0-21 tahun dan belum kawin (UU No. 4/1979)

b. Terlantar karena tidak mempunyai orang tua atau orang tua miskin sehingga tidak mampu mengurusnya.

c. Terlantar karena keluarganya mempunyai masalah sosial psikologis/keluarga retak.

d. Tidak sekolah atau putus sekolah.

e. Tidak atau belum bekerja bagi yang sudah berumur 18 tahun dan belum kawin.

f. Yang termasuk dalam kategori anak terlantar: a) anak yatim terlantar; b) anak piatu terlantar; c) anak yatim-piatu terlantar; d) anak putus sekolah, tidak sekolah atau di luar jangkauan sistem sekolah; dan e) anak yang terancam kemerosotan fungsi sosialnya.

\section{UPAYA PENINGKATAN KESEJAHTERAAN ANAK}

Kesejahteraan anak akan mudah tercipta saat anak sudah diperlakukan dengan baik. Maksud dari diperlakukan dengan baik disini adalah terpenuhinya semua kebutuhan dan hak dasar.Bukan hanya itu, anak juga dapat mengembangkan dirinya di lingkungan sosialnya.Seperti dikatakan oleh Zastrow, 2000 tentang kesejahteraan sosial:

"Kesejahteraan sosial adalah sebuah sistem yang meliputi program dan pelayanan yang membantu orang agar dapat memenuhi kebutuhan sosial, ekonomi, pendidikan dan kesehatan yang sangat mendasar untuk memelihara masyarakat."

Kesejahteraan anak juga dapat dilihat jika anak tersebut bisa merasa aman, bisa merasakan kasih sayang yang cukup dari kedua orang tuanya. Konsep kesejahteraan dan konsep martabat manusia yang dapat dilihat dari empat indikator menurut Nasikun (1993) yaitu:

(1) Rasa aman (security),

(2) Kesejahteraan (welfare),

(3) Kebebasan (freedom),

(4) Jati diri (Identity).

Perlindungan anak adalah segala kegiatan untuk menjamin dan melindungi anak dan hakhaknya agar dapat hidup, tumbuh, berkembang dan berpartisipasi secara optimal sesuai dengan harkat dan martabat kemanusiaan serta mendapat perlindungan dari kekerasan dan diskriminasi demi terwujudnya anak Indonesia yang berkualitas, berakhlak mulia dan sejahtera.

Berbagai upaya dilakukan oleh pemerintah Indonesia dalam mengurangi permasalahan perlindungan dan pemenuhan hak anak, seperti upaya untuk mengurangi pekerja anak di Indonesa. 
Sejak jaman dahulu hingga sekarang pemerintah terus melakukan inovasi-inovasi program-program yang bisa menjadi tolak ukur dalam pengentasan pekerja anak dengan cara peningkatan kualitas pendidikan.

Adapun upaya-upaya lainnya yang telah dilakukan terkait perlindungan dan pemenuhan hak anak yaitu:

1. Pemerintah membuat program, misalnya:

- Penerbitan akta kelahiran gratis bagi anak;

- Pendidikan tentang cara pengasuhan tanpa kekerasan kepada orangtua dan guru;

- Layanan kesehatan untuk anak;

- Meningkatkan anggaran pendidikan dasar dan menggratiskan biaya pendidikan dasar.

2. DPR/DPRD membuat UU/Perda untuk melindungi anak dari tindak kekerasan dan eksploitasi, mengancam pelaku dengan ancaman hukuman sehingga diharapkan bisa menimbulkan efek jera.

3. Jajaran penegak hukum (polisi, jaksa) dan penegak keadilan (hakim) memproses setiap pelanggaran hak anak dengan tegas, tanpa pandang bulu, dan memberi sanksi yg setimpal dengan pelanggaran yang dilakukan.

\section{PERAN PEKERJA SOSIAL}

Pekerja sosial adalah profesi yang bekerja untuk membantu masyarakat memberfungsikan keberfungsian sosialnya.Banyak masyarakat yang bermasalah untuk bisa mengatasi permasalahan hidupnya.Jack Claridge mengatakan bahwa:

"Pekerja sosial adalah sorang individu yang bertujuan untuk membantu orang-orang dalam masyarakat yang tidak mampu atau kesulitan dalam menangani masalah kehidupan yang mereka hadapi. Pekerja sosial dapat melakukan tugas mereka di sekolah, rumah sakit, organisasi, dan sektor publik lainnya."

Sedangkan untuk definisi pekerjaan sosial yang baru dan berskala internasional telah dibuat oleh Federasi Internasional Pekerja Sosial (International Federation of Social Workers, IFSW) dan didukung oleh Ikatan Pekerja Sosial Amerika Serikat (National Association of Social Workers, NASW) pada tahun 2000 serta diterima oleh Ikatan Pekerja Sosial Profesional Indonesia (IPSPI) pada Kongres II IPSPI 2003, menyatakan bahwa:

"The social work profession promotes social change, problem solving in human relationships and the empowerment and liberation of people to enhance well-being. Utilising theories of human behavior and social systems, social work intervenes at the points where people interact with their environments. Principles of human rights and social justice are fundamental to social work" (DuBois \& Miley, 2005: 4).

Dalam pengertian diatas disebutkan bahwa profesi pekerjaan sosial mempromosikan perubahan sosial, pemecahan masalah pada relasi manusia dan pemberdayaan serta pembebasan manusia untuk meningkatkan kesejahteraan.Prinsip-prinsip hak azasi manusia dan keadilan sosial adalah fundamental bagi pekerjaan sosial.Pekerja sosial berusaha membantu anak, tidak bekerja dengan kekosongan.

\section{KESIMPULAN}

Perlindungan anak patut diperhatikan lebih detail lagi karena pada kenyataannya, dewasa ini masih sangat banyak kasus-kasus yang berhubungan dengan pelanggaran hak anak, seperti kasus pekerja anak, anak terlantar, pekerja seks komersial yang dilakukan oleh anak-anak, dan masih tingginya jumlah anak jalanan. Perlindungan anak menjadi tanggung jawab bersama, bukan hanya kewajiban orang tua saja. 
Undang-Undang Perlindungan Anak (UUPA) juga diperlukan untuk menegaskan adanya kewajiban bagi negara, pemerintah, masyarakat, keluarga, orangtua dan anak, mengingat kewajiban memberikan perlindungan anak walaupun sudah disadari merupakan kewajiban bersama, namun perlu diberikan landasan hukum secara khusus disamping yang sudah dicantumkan dalam pasal-pasal UUD 1945 atau dalam berbagai Peraturan Perundang-Undangan yang lain, agar dapat menjamin pelaksanaannya secara komprehensif dan tepat penanganan serta sasaranna, yang harus dilakukan oleh negara, pemerintah, masyarakat, keluarga dan orangtua anak. Selain itu, perlu adanya keseimbangan antara perlindungan hak anak dan pemberian kewajiban bagi anak dalam kapasitas mendidik anak.Oleh karena itu, disamping dilindungi hak-haknya, agar tidak menjadi salah asuh, salah arah, maka perlu ditujukkan juga kewajiban yang perlu dilaksanakan oleh anak.

Perlu adanya upaya untuk menjalin kerjasama yang positif, baik dengan instansi pemerintah maupun dengan LSM sebagai bagian dari upaya aparat penegak hukum dalam melakukan diversi dan restorative justice.Sehingga diversi dan restorative justice dapat dipromosikan dan dikembangkan sebagai solusi penyelesaian perkara anak yang berkonflik dengan hukum. Jika peningkatan upaya perlindungan anak dapat diatasi dengan baik, maka kesejahteraan anak pun akan lebih mudah dicapai. Karena selama ini nyartanya banyak pelanggaran hak anak yang terjadi disebabkan oleh minimnya atau masih tidak jelasnya perlindungan terhadap anak.

\section{DAFTAR PUSTAKA}

\section{Sumber Buku:}

Suharto, Edi dan Edi Suhanda. 2009. Praktek Pekerjaan Sosial dengan Anak. Jakarta: Pustaka Society.

Astuti, M. Kebijakan Kesejahteraan dan Perlindungan Anak, Studi Kasus Evaluasi Program Kesejahteraan Sosial Anak. 2013. Jakarta: P3KS Press

\section{Sumber lain:}

Jumlah anak telantar di seluruh Indonesia yang masih sangat tinggi, http://www.republika.co.id/berita/nasional/umum/12/04/23/m2xabh-duh-jumlah-anakterlantar-Indonesia-masih-4-juta-lebih

Undang - Undang Republik Indonesia No. 23 tahun 2002 tentang Perlindungan Anak

Situs yang membahas tentang perlindungan perempuan dan anak: http://disnakertrans.kaltimprov.go.id/berita-203-sosialisasi-kebijakan-hukum-tentangperlindungan-perempuan-dan-anak.html

Konvensi Hak Anak oleh UNICEF pada tahun 1989 